\title{
Clinical studies regarding COVID-19 in Belgium
}

\section{To the Editor}

The severe acute respiratory syndrome coronavirus 2 (SARS-CoV-2), causing coronavirus disease 2019 (COVID-19), arrived in Belgium early February 2020 [1]. This was the start of an epidemic that, by May $2^{\text {nd }}, 2021$, would be responsible for 993,434 confirmed cases; 70,384 hospitalisations and 24,258 fatalities [2]. After more than one year of research into the disease and its causative agent, a lot of progress has been made in management and treatment of COVID-19 [3]. As of December 21 $1^{\text {st }}, 2020$, the Belgian Federal Agency for Medicines and Healthcare products (FAHMP) reported that 32 clinical drug trials, 6 clinical vaccine trials and 5 clinical studies with medical devices and/or in vitro diagnostics were authorized [4]. Continued research efforts are essential to tackling the persisting pandemic.

To obtain an insight into the clinical studies already performed in Belgium, the clinical trials database of FAHMP was searched for "covid-19". To identify additional studies not involving investigational medicinal products (IMPs), the clinicaltrials.gov database was searched for "COVID-19", "COVID" and "SARS-CoV-2". The results were filtered for studies in Belgium that were completed, suspended or terminated.

Thirty-three unique studies were retrieved from the FAHMP register (Supplementary materials, Table S1). Of these studies, $23(69.70 \%)$ were being conducted at multiple sites in Belgium. This means that in a large majority of the studies, there was a cooperation between different institutions. Monocentric studies were often carried out in centres with specific expertise. Twenty-six (78.79\%) studies utilized randomi- sation. Despite being only part of study design, this observation suggests that the urgency by which knowledge about COVID-19 is needed, did not negatively impact the scientific rigor of the research performed.

The number of studies per phase of development studies are shown in Figure 1. Five of the extracted studies $(15,15 \%)$ were in phase I (human pharmacology). Most of these studies investigated the safety and immunogenicity of vaccine candidates. Nine (27.27\%) studies were only in phase II (therapeutic exploratory). These studies investigated a wide variety of treatment strategies to tackle COVID-19, ranging from antiviral drugs to cell therapy. Phase III (therapeutic confirmatory) studies accounted for 6 (18.18\%) of the total number of studies. These studies looked into the safety and efficacy of several treatments for disease management and prevention. Five $(15.15 \%)$ studies were described being both phase II \& III. Finally, 8 studies were in phase IV (therapeutic use). Based on these observations, it can be stated that COVID-19 research in all phases of the development process is being conducted in the Belgian territory.

Twenty-eight completed or terminated studies were conducted in Belgium according to the clinicaltrials.gov database (Supplementary materials, Table S2). Completed studies numbered 25 (89.29\%) and terminated studies $3(10.71 \%)$. The three terminated studies investigated hydroxychloroquine as a treatment, a COVID-19 vaccine and the performance of three sampling methods. Unfortunately, none of the completed studies had results available. From the identified studies, it is clear that a lot of different research interventions have been used for COVID-19 research, including ques- 
Phase of studies authorized by FAMHP

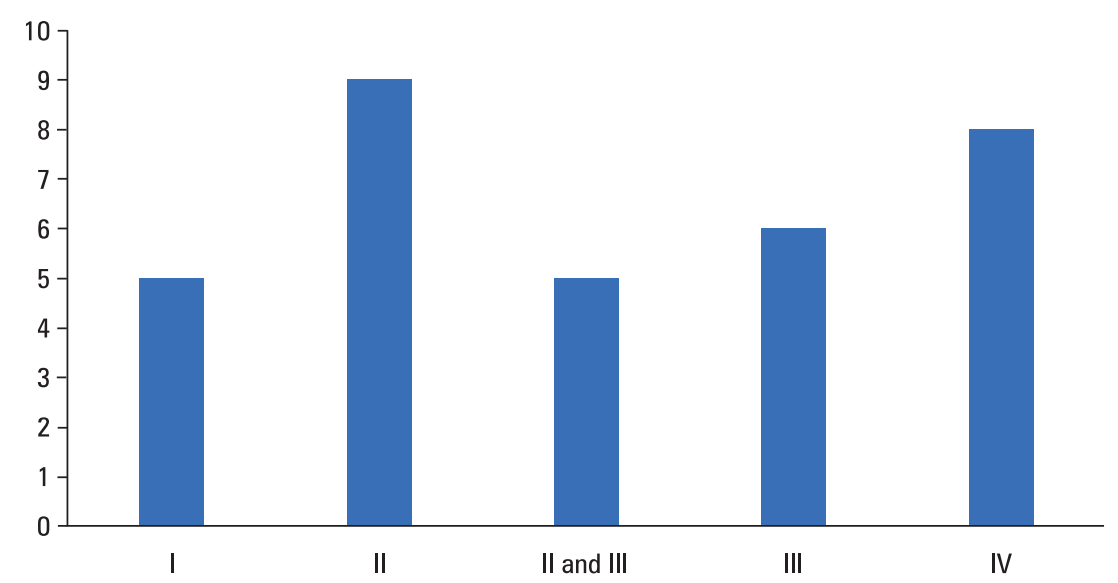

Figure 1. Number of studies approved by Federal Agency for Medicines and healthcare products (FAMHP) per phase

tionnaires and drug treatment. This is linked to the wide range of research topics of the studies, which ranged from discontinuation of fertility treatment to quality of life of oncology patients during the pandemic. A lot of aspects besides the purely medical and virological questions about the pandemic are being investigated.

Eleven (39.28\%) of the studies were interventional while 17 were observational (60.71\%). This means that several types of study design are used to investigate the COVD-19 pandemic.

In general, it is clear that a lot of research on COVID-19 has been conducted in Belgium. The studies are diverse in scope and methods. A more comprehensive analysis of the research conducted, could provide directions for further research. Additionally, systematic reviews and meta-analyses could synthesize the different studies already conducted.

\section{Conflict of interest}

The authors do not have a conflict of interest.

\section{References:}

1. Coronavirus COVID-19. One repatriated Belgian has tested positive for the novel coronavirus. Available online: www. info-coronavirus.be/en/news/one-repatriated-belgian-has-tested-positive-for-the-novel-coronavirus/. [Last accessed at: 26.04.2021].

2. COVID-19 - Epidemiologisch Bulletin Van 6 Juli 2021. Available online: https://covid-19.sciensano.be/sites/default/files/Covid19/ Meest\%20recente\%20update.pdf. [Last accessed at 02.05.2021].

3. Panovska-Stavridis I, Ridova N, Stojanoska T, et al. Insight in the Current Progress in the Largest Clinical Trials for COVID-19 Drug Management (As of January 2021). Pril (Makedon Akad Nauk Umet Odd Med Nauki). 2021; 42(1): 5-18, doi:10.2478/ prilozi-2021-0001.

4. Fagg. Federaal agentschap voor geneesmiddelen en gezondheidsproducten. Overzicht van de verschillende activiteiten van het FAGG in onderzoek en ontwikkeling rond COVID-19. Available online: www.fagg.be/nl/MENSELIJK_gebruik/geneesmiddelen/geneesmiddelen/covid_19/overzicht_van_de_verschillende_activiteiten. [Last accessed 26.04.2021]. 